\title{
Trophic niche overlap between sympatric harbour seals (Phoca vitulina) and grey seals (Halichoerus grypus) at their Southern European limit range (Eastern English Channel)
}

\author{
Yann Planque ${ }^{1}$, Jérôme Spitz ${ }^{1}$, Matthieu Authier ${ }^{2}$, Cécile Vincent ${ }^{1}$, and Florence Caurant ${ }^{1}$ \\ ${ }^{1}$ Centre d'Etudes Biologiques de Chizé \\ ${ }^{2}$ Observatoire PELAGIS
}

November 11, 2020

\begin{abstract}
Competition between the sympatric harbour (Phoca vitulina) and grey seals (Halichoerus grypus) is thought to underlie some recent local declines of the former while the population of the latter remains stable or increases. A better understanding of the interactions between these two species is critical to elucidate current changes. This study aims at identifying and quantifying the niche overlap between harbour and grey seals at their Southern European limit range, in the baie de Somme (Eastern English Channel, France), in a context of exponential increase in the number of resident harbour seals and visiting grey seals. Isotopic niche overlap was quantified between both species using whisker $\delta 13 \mathrm{C}$ and $\delta 15 \mathrm{~N}$ isotopic values, taking intra- and interindividual variability into account. Dietary overlap was quantified from scat contents using hierarchical clustering. A high degree of trophic niche overlap was identified between both species. The narrower isotopic niche of harbour seals was nested within that of grey seals (58.2\% [CI95\%: 22.7-100\%] overlap). Six diet clusters were identified from scat content analysis. Two of them gathered most of harbour seals' scats (85.5 \% [80.3-90.2\%]) and around half of grey seals' ones (46.8\% [35.1-58.4\%]) that almost exclusively contained benthic flatfish. Consumption of this type of prey was identified here to be the root cause of trophic overlap. This highlighted the potential for competition between the two species at their Southern European limit range, linked to foraging on benthic flatfish, in coastal waters close to their haulout sites, especially during spring/summer. We suggest that (1) interspecific competition for prey could occur/increase in the future if the number of grey and harbour seals still increase and/or if flatfish supply decrease in this area, and (2) harbour seals would be disadvantaged in such a case if they do not adapt, as being specialised on flatfish at the colony scale.
\end{abstract}

\section{Hosted file}

Manuscript_Planque_et_al [NICHE OVERLAP] _2020-11-10.pdf available at https://authorea. com/users/374802/articles/492239-trophic-niche-overlap-between-sympatric-harbour-sealsphoca-vitulina-and-grey-seals-halichoerus-grypus-at-their-southern-european-limit-rangeeastern-english-channel 


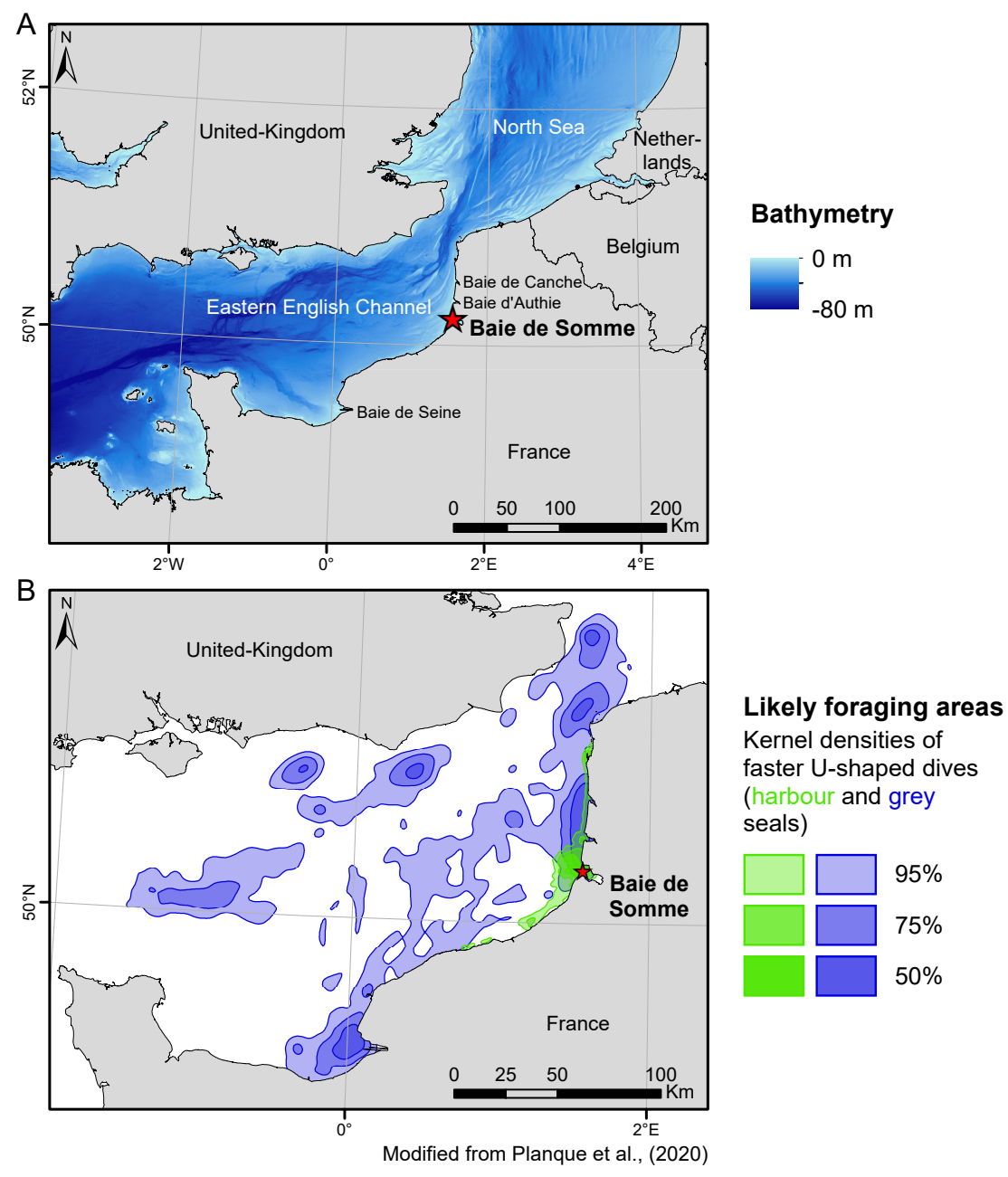




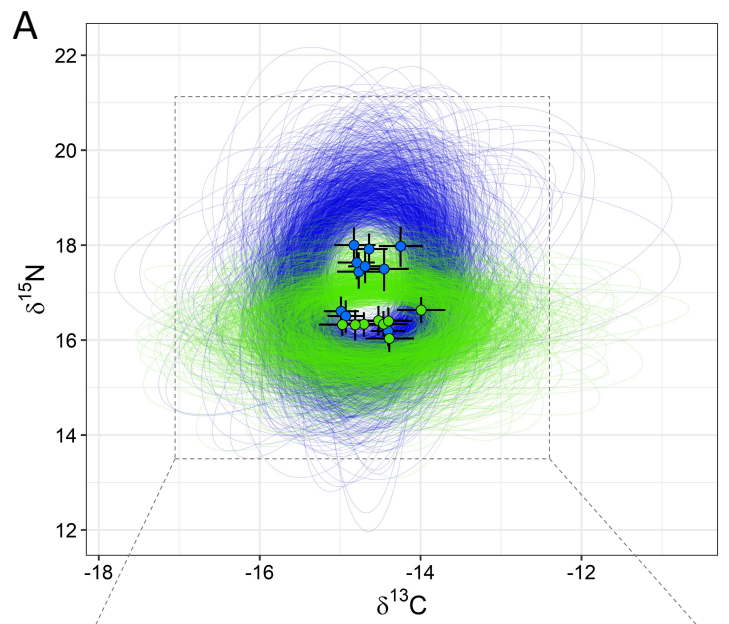

Model ellipses $(n=1000)$ characterising isotopic niches

- Harbour seals

- Grey seals

Predicted values for observed individuals

- Harbour seals $(n=8)$

Grey seals $(n=10)$

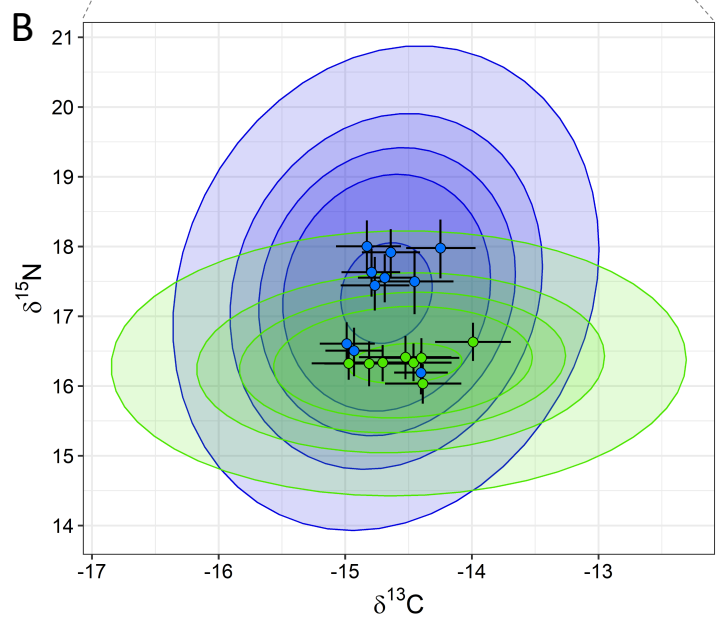

Probability belonging to the isotopic niche (harbour and grey seals)

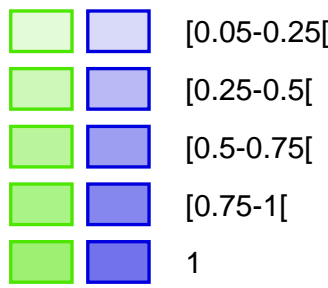

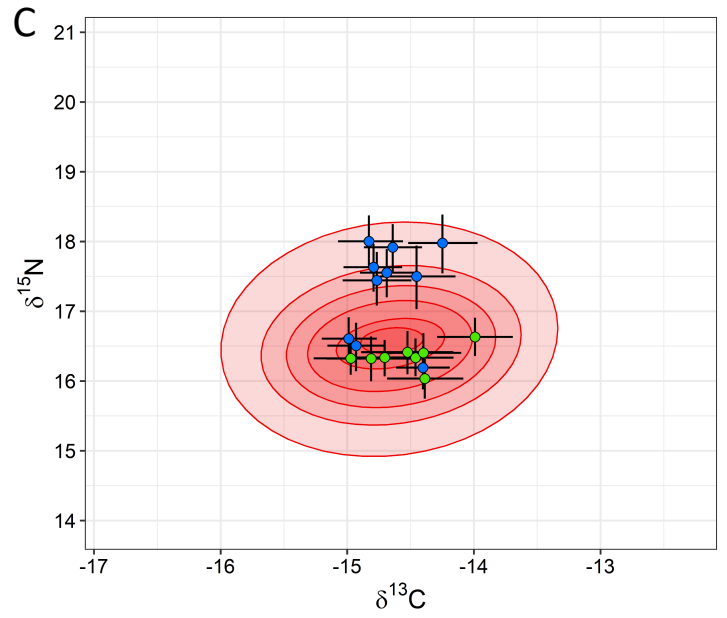

Probability of interspecific overlap

\begin{tabular}{ll}
\hline & {$[0.05-0.25[$} \\
\hline & {$[0.25-0.5[$} \\
$\square$ & {$[0.5-0.75[$} \\
$\square \quad$ & {$[0.75-0.95[$} \\
$\square \quad$ & {$[0.95-0.99[$} \\
$\square \quad$ & {$[0.99-1]$}
\end{tabular}



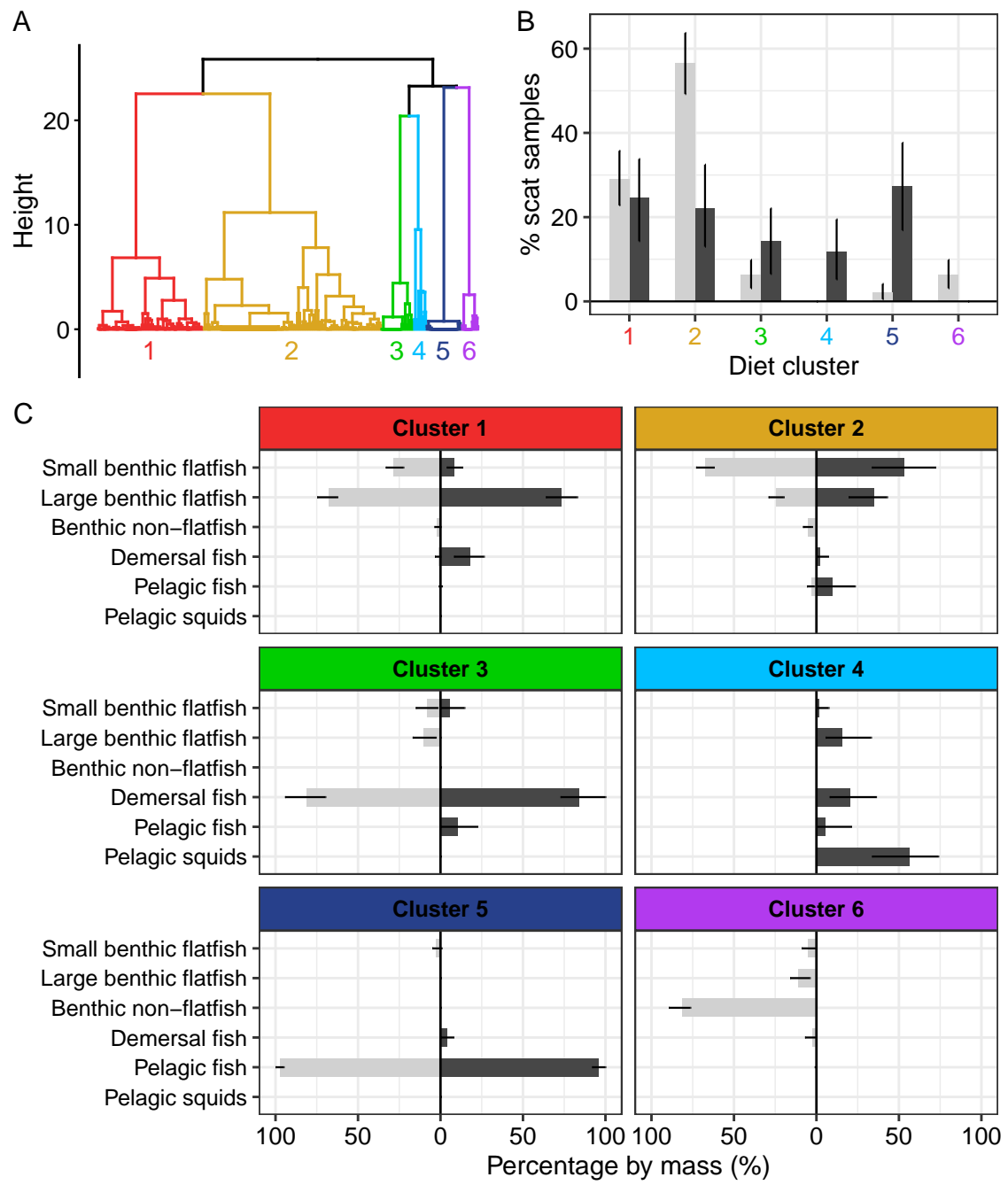

Harbour seals

Grey seals 

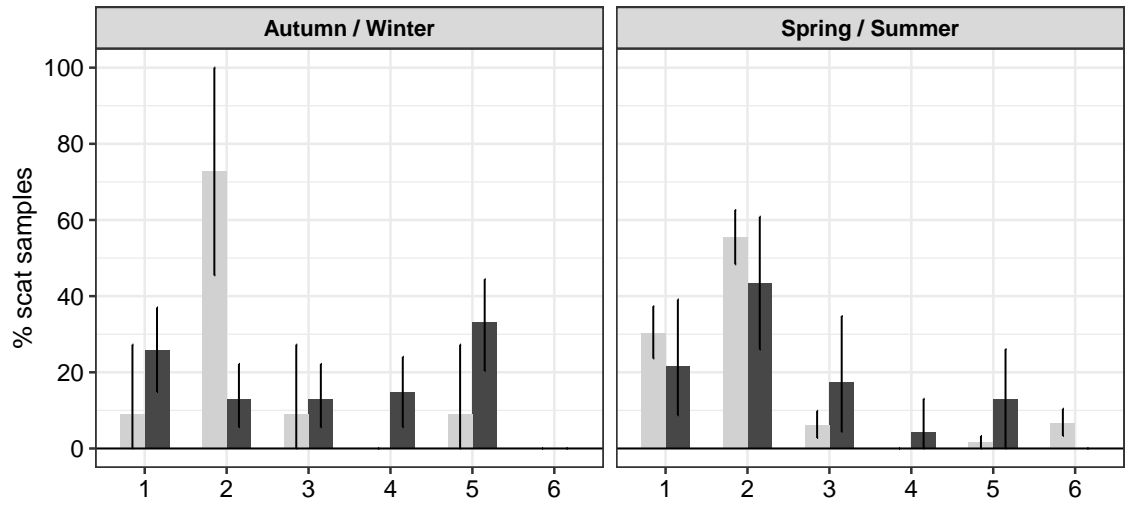

Species Harbour seals

Grey seals

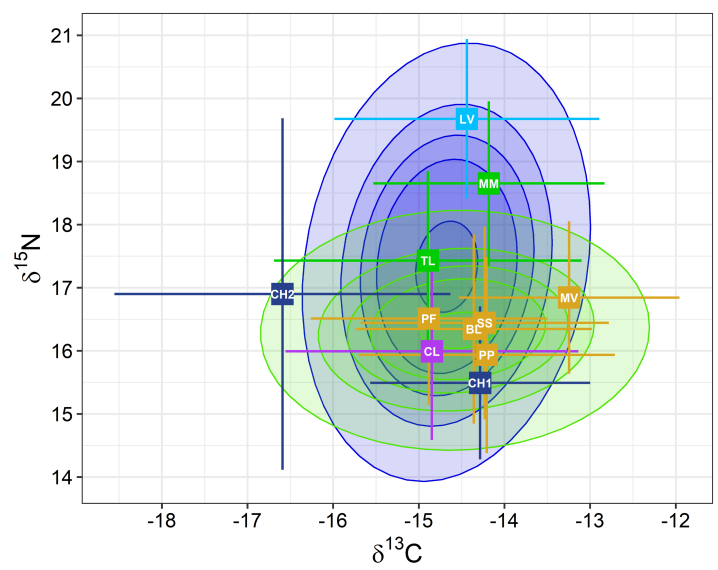

Probability belonging to

the isotopic niches

(harbour and grey seals)

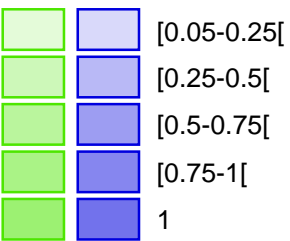

Source of isotopic data for potential prey: Kopp et al., (2015)
Applied TEF from prey to predator: $\mathrm{\delta}^{13} \mathrm{C}=+2.4 \pm 1.3, \delta^{15} \mathrm{~N}=+2.6 \pm 1.4$ (Lerner et al., 2018)

Isotopic composition of potential seal prey species (mean \pm SD) with applied TEF

- Benthic flatfish

PP Pleuronectes platessa

PF Platichthys flesus

SS Solea solea

MV Microchirus variegatus

BL Buglossidium luteum \pm Benthic non-flatfish

CL Callionymus lyra

Demersal fish

MM Merlangius merlangus

TL Trisopterus luscus

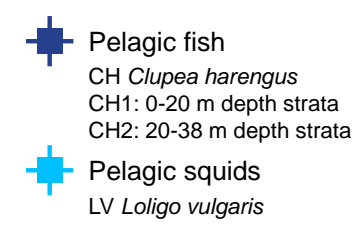

$\mathrm{CH}$ Clupea harengus $\mathrm{CH} 1: 0-20 \mathrm{~m}$ depth strata

Pelagic squids

LV Loligo vulgaris

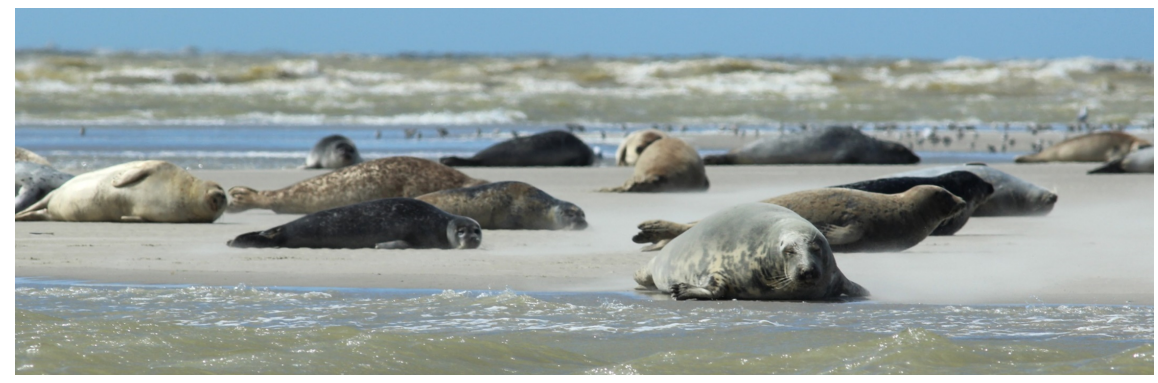

